\title{
Prevalence and Characteristics of Lung Involvement on High Resolution Computed Tomography in Patients with Ankylosing Spondylitis: A Systematic Review
}

\author{
Abdellah El Maghraoui ${ }^{1}$ and Mohamed Dehhaoui ${ }^{2}$ \\ ${ }^{1}$ Rheumatology Department, Military Hospital Mohammed V, P.O. Box 1018, Rabat, Morocco \\ ${ }^{2}$ Statistics Department, Hassan II Agronomic Institute, Rabat, Morocco \\ Correspondence should be addressed to Abdellah El Maghraoui, aelmaghraoui@gmail.com
}

Received 5 September 2011; Accepted 12 December 2011

Academic Editor: Carol Feghali-Bostwick

Copyright (C) 2012 A. El Maghraoui and M. Dehhaoui. This is an open access article distributed under the Creative Commons Attribution License, which permits unrestricted use, distribution, and reproduction in any medium, provided the original work is properly cited.

\begin{abstract}
To determine the prevalence of lung involvement and the spectrum of abnormalities revealed on HRCT in patients with AS, a systematic literature review was conducted in the Medline database up to May 2009 and in the abstracts of rheumatology scientific meetings (2006-2008). A hand search of references was also performed. Among the 264 selected articles, 10 articles (303 patients) allowed a calculation of the prevalence of lung abnormalities on thoracic HRCT in AS. A total of 185 patients $(61 \%)$ had an abnormal thoracic HRCT: upper lobe fibrosis in 21 (6.9\%), emphysema in 55 (18.1\%), bronchiectasis in 33 (10.8\%), and ground glass attenuation in $34(11.2 \%)$. Non specific interstitial abnormalities were observed in $101(33 \%)$ patients. The most common observed abnormalities were pleural thickening (52\%), parenchymal bands (45\%) and interlobular septal thickening (30\%). Only the prevalence of upper lobe fibrosis increased significantly with disease duration ( 3 studies). Mild and non-specific interstitial abnormalities on thoracic HRCT are common in patients with AS, even in patients with early disease and without respiratory symptoms.
\end{abstract}

\section{Introduction}

Ankylosing spondylitis (AS) is a chronic rheumatic disorder characterized by inflammation of the enthesis (especially of the axial skeleton) and sometimes the joints, which may lead to ankylosis [1]. AS is a multisystemic disease and extraarticular features include uveitis, carditis, colitis, and osteoporosis [2-4]. Lung involvement is now a wellrecognized extra-articular feature of AS. It was initially described in 1941 [5]. However, it was considered as an extra-articular manifestation of the disease only since 1965 [6]. The prevalence of pleuropulmonary involvement in AS varies considerably $(0-30 \%)$ in the medical literature. The most frequently recognized pleuropulmonary manifestations are upper lobe fibrosis, mycetoma formation, and pleural thickening [7-12]. The advent of high resolution computed tomography (HRCT) in the mid 1980s has allowed physicians to examine the entire lung parenchyma and pleura in many conditions with diffuse lung disease using a noninvasive method [13].

The objective of this analysis was to determine the prevalence of lung involvement and the spectrum of abnormalities revealed on HRCT in patients with AS according to the disease duration and to describe its clinical characteristics by a systematic literature review.

\section{Material and Methods}

To identify relevant studies, allowing calculation of the prevalence of lung involvement in AS or to determine its characteristics or both, a systematic analysis of literature was performed in May 2009.

2.1. Literature Search Strategy. Publications were identified in the PubMed Medline database up to May 2009 and in the abstracts of EULAR (European League Against Rheumatism) 


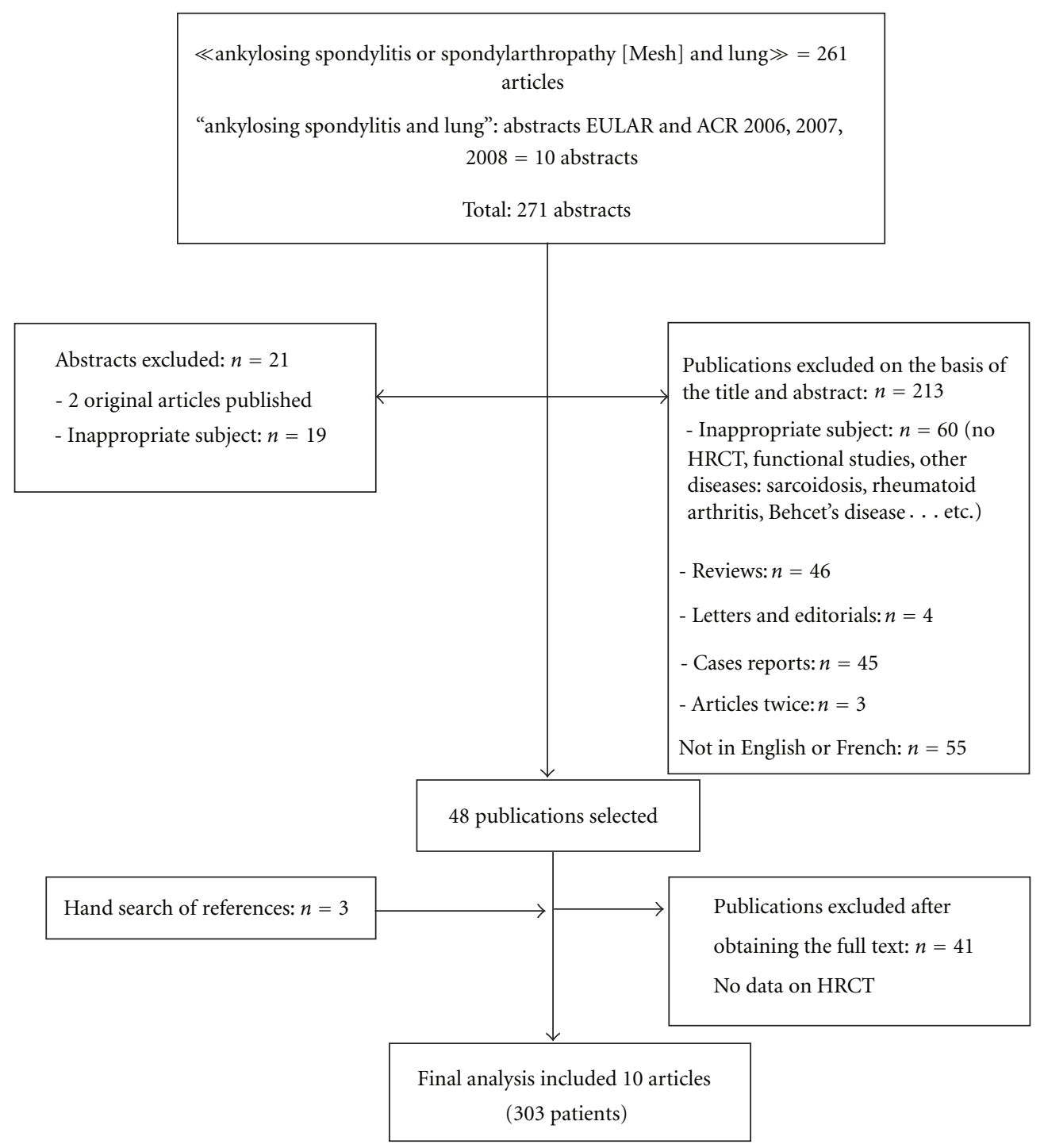

FIgURE 1: Flowchart summarizing the search process.

and the ACR (American College of Rheumatology) scientific meetings of the years 2006, 2007, and 2008. Two searches were carried out in the Medline database which used the following key words: for the first search "spondylarthritis" or "ankylosing spondylitis" and "interstitial lung disease" or "apical fibrosis" (limits were English, French, humans); for the second search "spondylarthritis" or "ankylosing spondylitis" and "thoracic CT scan" (limits were English, French, humans). Original articles were selected if they reported the prevalence and/or the characteristics of lung involvement on thoracic HRCT in AS. The analysis concerned adults over 16 years old; studies concerning juvenile arthritis were excluded. Lastly, a hand search of references was also performed.

2.2. Data Collection. The articles were analysed by one author (A. El Maghraoui) according to a predetermined abstraction sheet. The following items were collected: num- ber of AS patients (and criteria for the diagnosis), number of patients reported as having lung involvement on HRCT, sex, age at the moment of the study, disease duration, and characteristics of lung involvement on HRCT.

2.3. Statistical Analysis. Statistics were descriptive. The prevalence of lung involvement on HRCT was calculated as the number of patients with AS presenting one or more lesion on HRCT over the total number of patients with AS. Standard deviations and means were calculated based on available data.

\section{Results}

3.1. Article Selection. The Medline database and the congress abstracts search yielded 261 articles. With the hand search of references, a total of 10 articles were entered in the analysis (Figure 1). Main reasons for exclusion were reviews 
TABLE 1: Prevalence of thoracic HRCT abnormalities in patients with AS.

\begin{tabular}{|c|c|c|c|c|c|c|c|c|c|c|c|}
\hline & 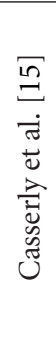 & 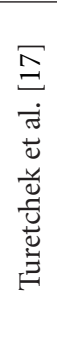 & 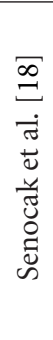 & 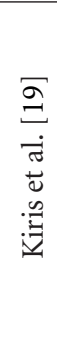 & 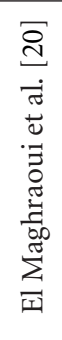 & 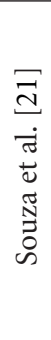 & 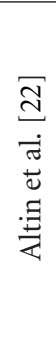 & 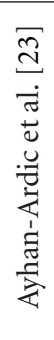 & 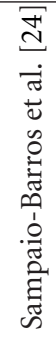 & 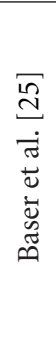 & Total: $n(\%)$ \\
\hline$N$ & 26 & 21 & 20 & 28 & 55 & 17 & 38 & 20 & 52 & 26 & 303 \\
\hline $\begin{array}{l}\text { Prevalence of abnormalities on } \\
\text { HRCT }\end{array}$ & 18 & 15 & 17 & 18 & 31 & 15 & 27 & 10 & 21 & 13 & $185(61)$ \\
\hline Apical fibrosis & 2 & & 3 & & 5 & 1 & 5 & 2 & 1 & 2 & $21(6.9)$ \\
\hline Emphysema & 4 & 2 & 9 & & 5 & 6 & 13 & 2 & 5 & 9 & $55(18.1)$ \\
\hline Brochiectasis & 6 & 2 & 3 & 2 & 4 & 2 & & 2 & 4 & 8 & $33(10.8)$ \\
\hline Ground glass attenuation & 2 & 1 & 6 & 2 & 2 & & 14 & & & 7 & $34(11.2)$ \\
\hline $\begin{array}{l}\text { Non specific lung interstitial } \\
\text { abnormalities }\end{array}$ & 11 & 6 & 9 & 10 & 26 & 10 & 19 & & 10 & & $101(33.3)$ \\
\hline Lymphadenopathy & 3 & & & & & & & & 6 & & $9(2.9)$ \\
\hline Pleural thickening & 1 & 6 & 9 & & 13 & 3 & 13 & & 4 & 4 & $53(17.4)$ \\
\hline Micronodules & 1 & 2 & 8 & 7 & 7 & 1 & & & 3 & 4 & $33(10.8)$ \\
\hline Pulmonary cysts & & & & & & 3 & & & 1 & & $4(1.3)$ \\
\hline Bronchial wall thickening & 4 & 6 & & 2 & & & 12 & & & & $24(7.9)$ \\
\hline Sub-pleural band & 6 & & & & 6 & & & & & & $12(3.9)$ \\
\hline Parenchymal band & 8 & & 3 & 5 & 13 & & 14 & & & 3 & $46(15.1)$ \\
\hline Irregular interfaces & 3 & & & & 4 & & & & & & $7(2.3)$ \\
\hline Blebs & 3 & & & & 7 & & & & & & $10(3.3)$ \\
\hline Intrelobular septal thickening & 7 & 7 & & 1 & & & 16 & & & & $31(10.2)$ \\
\hline Linear septal thickening & & 6 & 9 & & & & & & & 6 & $21(6.9)$ \\
\hline Pleural tags & 4 & & & & & & & & & & $4(1.3)$ \\
\hline
\end{tabular}

and case reports $(42.7 \%)$, articles not related to AS or lung involvement on HRCT (28.1\%).

3.2. Prevalence. To calculate prevalence, a total of 10 articles were assessed. All the studies were cross-sectional. The total number of patients with AS was 303. The diagnosis of AS was based on modified New York criteria for all the patients [14]. Of 303 patients, $258(85.1 \%)$ were male. Mean (SD) age was 40.7 (6.2) years. Mean disease duration was 11.7 (5.2) years. Only $18(5.9 \%)$ patients were reported to have pulmonary symptoms, 73 (24\%) were current smokers and 41 (13.5\%) ex-smokers.

A total of 185 patients $(61 \%)$ was reported as having an abnormal thoracic HRCT imaging. Among these patients, upper lobe fibrosis were observed in 21 (6.9\%), emphysema in $55(18.1 \%)$, bronchiectasis in $33(10.8 \%)$, and ground glass attenuation in 34 (11.2). Nonspecific interstitial abnormalities were observed in 101 (33\%) patients. The most common observed abnormalities were pleural thickening (52\%), parenchymal band (45\%), and intrelobular septal thickening (30\%) (Table 1).

Only 3 studies analyzed the prevalence of HRCT abnormalities according to disease duration. Among the 75 pa-
TABle 2: Prevalence of thoracic HRCT abnormalities in patients with AS according to disease duration.

\begin{tabular}{lcccc}
\hline Disease duration & $<5$ yrs & $5-10$ yrs & $>10$ yrs & $P$ \\
\hline Number of patients at risk & 50 & 18 & 23 & \\
Ground glass attenuation & $9(18)$ & $2(11.1)$ & $4(17.3)$ & 0.855 \\
Upper lobe fibrosis & $3(6)$ & $2(11.1)$ & $5(21.7)$ & 0.049 \\
Brochiectasis & $9(18)$ & $1(5.5)$ & $5(21.7)$ & 0.881 \\
Emphysema & $11(22)$ & $3(16.6)$ & $8(34.7)$ & 0.309 \\
\hline
\end{tabular}

tients at risk, the prevalence of upper lobe fibrosis increased with disease duration (Table 2).

\section{Discussion}

This systematic literature review reports the prevalence and characteristics of chest HRCT abnormalities in AS. In this systematic analysis, the prevalence of pulmonary abnormalities in AS was high: $61 \%$ for a mean disease duration of 11.7 (5.2) years. Upper lobe fibrosis, with or without cavitation, was a rare HRCT finding reported in $6.9 \%$. Prevalence increased with disease duration in the few 
studies where data were available. The main characteristic of pulmonary abnormalities in AS was the high frequency of mild nonspecific interstitial abnormalities. In this systematic analysis, parenchymal bands and sparse thickening of the interlobular septa, characterized as linear opacities, were the most frequent findings considered as nonspecific interstitial lung disease [15-26].

The interpretation of prevalence must take into account disease duration. However, few studies analyzed the prevalence of lung abnormalities on HRCT according to disease duration. Indeed, in this analysis the prevalence of upper lobe fibrosis in AS increased with the mean disease duration; this prevalence reached $21 \%$ for a mean disease duration $>10$ years. This was not the case for the other observed abnormalities. However, it should be noted that these analyses concerned mean disease duration, and not true categories of disease duration, which is one of the limitations of this work, which is unavoidable in systematic literature reviews.

Smoking-induced lung disease is a complex group of disorders, varying from the well-known entity of chronic obstructive pulmonary disease to more recently described interstitial lung diseases which may resemble to the reported abnormalities described here [27]. Among the studied patients in this systematic review, about 37\% had a history of smoking. However, no differences in prevalence of HRCT lung abnormalities were noted between smokers and no smokers.

The main limit of this systematic literature review is a possible selection bias. None among the published studies had a control group. Seven studies included consecutive patients with AS without history of pulmonary symptoms and excluded patients with history of tuberculosis, earlier pneumonia, and exposure to dust or inhaled gases, while 2 studies included patients even when patients had pulmonary symptoms and one study selected patients with no history of smoking. With regard to the evaluation of CT abnormalities, another limitation is that different scanners were used which may have hampered precise evaluation of subtle lung changes. The analysis of images generated with different reconstruction algorithms may have affected the detection of mild ground-glass opacity.

The effect of anti-TNF blockers on interstitial lung fibrosis and other abnormalities has never been evaluated. However, this issue may become even more important as these agents are now widely prescribed for AS [28, 29]. Moreover, many recent case reports described contrasting effects on pulmonary fibrosis in patients with rheumatoid arthritis (RA). Ostor et al. [30] reported fatal exacerbation of RA-associated fibrosing alveolitis in three patients receiving infliximab. On the other hand, Bargagli et al. [31] described a beneficial effect of infliximab in the treatment of RA associated with interstitial lung disease.

The administration of anti-TNF agents is associated with an increased risk of reactivation of latent tuberculosis even though the measures recommended to screen and to prevent this reactivation have been shown to be effective [32]. Thus, in clinical practice thoracic HRCT may be useful to identify a suspicious abnormality in chest X-rays, especially when
anti-TNF therapy is planned. Clinicians must be aware of the HRCT abnormalities observed in AS, which must not be confounded with tuberculosis lesions.

In summary, this systematic review revealed a great percentage of defined as well as mild and nonspecific interstitial abnormalities on thoracic HRCT undetectable on plain radiography in patients with AS. These lesions are common even in patients with early disease and without respiratory symptoms. The significance of such changes is unknown and must await prospective longitudinal studies to determine their natural history. Among the observed lung abnormalities, only apical fibrosis seemed to be more prevalent with increasing disease duration.

\section{Conflict of Interests}

The authors declare that they have no conflict of interests.

\section{References}

[1] J. Braun and J. Sieper, "Ankylosing spondylitis," Lancet, vol. 369, no. 9570, pp. 1379-1390, 2007.

[2] F. Brunner, A. Kunz, U. Weber, and R. Kissling, "Ankylosing spondylitis and heart abnormalities: do cardiac conduction disorders, valve regurgitation and diastolic dysfunction occur more often in male patients with diagnosed ankylosing spondylitis for over 15 years than in the normal population?" Clinical Rheumatology, vol. 25, no. 1, pp. 24-29, 2006.

[3] I. Ghozlani, M. Ghazi, A. Nouijai et al., "Prevalence and risk factors of osteoporosis and vertebral fractures in patients with ankylosing spondylitis," Bone, vol. 44, no. 5, pp. 772-776, 2009.

[4] N. Zeboulon, M. Dougados, and L. Gossec, "Prevalence and characteristics of uveitis in the spondyloarthropathies: a systematic literature review," Annals of the Rheumatic Diseases, vol. 67, no. 7, pp. 955-959, 2008.

[5] C. L. K. Dunham and F. G. Kautz, "Spondylarthritis ankylopoietica: a review and report of twenty cases," The American Journal of the Medical Sciences, vol. 201, pp. 232-250, 1941.

[6] A. H. Campbell and C. B. MacDonald, "Upper lobe fibrosis associated with ankylosing spondylitis," British Journal of Diseases of the Chest, vol. 59, no. 2, pp. 90-101, 1965.

[7] A. El Maghraoui, "Pleuropulmonary involvement in ankylosing spondylitis," Joint Bone Spine, vol. 72, no. 6, pp. 496-502, 2005.

[8] E. Rosenow, C. V. Strimlan, J. R. Muhm, and R. H. Ferguson, "Pleuropulmonary manifestations of ankylosing spondylitis," Mayo Clinic Proceedings, vol. 52, no. 10, pp. 641-649, 1977.

[9] D. Davies, "Ankylosing spondylitis and lung fibrosis," The Quarterly Journal of Medicine, vol. 41, no. 164, pp. 395-417, 1972.

[10] D. K. Boushea and W. R. Sundstrom, "The pleuropulmonary manifestations of ankylosing spondylitis," Seminars in Arthritis and Rheumatism, vol. 18, no. 4, pp. 277-281, 1989.

[11] G. Hillerdal, "Ankylosing spondylitis lung disease-an underdiagnosed entity?" European Journal of Respiratory Diseases, vol. 64 , no. 6, pp. 437-441, 1983.

[12] N. Feltelius, H. Hedenstrom, G. Hillerdal, and R. Hallgren, "Pulmonary involvement in ankylosing spondylitis," Annals of the Rheumatic Diseases, vol. 45, no. 9, pp. 736-740, 1986.

[13] D. A. Lynch, J. D. Godwin, S. Safrin et al., "High-resolution computed tomography in idiopathic pulmonary fibrosis: 
diagnosis and prognosis," American Journal of Respiratory and Critical Care Medicine, vol. 172, no. 4, pp. 488-493, 2005.

[14] S. van der Linden, H. A. Valkenburg, and A. Cats, "Evaluation of diagnostic criteria for ankylosing spondylitis. A proposal for modification of the New York criteria," Arthritis and Rheumatism, vol. 27, no. 4, pp. 361-368, 1984.

[15] I. P. Casserly, H. M. Fenlon, E. Breatnach, and S. M. Sant, "Lung findings on high-resolution computed tomography in idiopathic ankylosing spondylitis-correlation with clinical findings, pulmonary function testing and plain radiography," British Journal of Rheumatology, vol. 36, no. 6, pp. 677-682, 1997.

[16] H. M. Fenlon, I. Casserly, S. M. Sant, and E. Breatnach, "Plain radiographs and thoracic high-resolution CT in patients with ankylosing spondylitis," American Journal of Roentgenology, vol. 168, no. 4, pp. 1067-1072, 1997.

[17] K. Turetschek, W. Ebner, D. Fleischmann et al., "Early pulmonary involvement in ankylosing spondylitis: assessment with thin-section CT," Clinical Radiology, vol. 55, no. 8, pp. 632-636, 2000.

[18] Ö. Şenocak, M. Manisali, D. Özaksoy, C. Sevinç, and E. Akalin, "Lung parenchyma changes in ankylosing spondylitis: demonstration with high resolution CT and correlation with disease duration," European Journal of Radiology, vol. 45, no. 2, pp. 117-122, 2003.

[19] A. Kiris, S. Ozgocmen, E. Kocakoc, O. Ardicoglu, and E. Ogur, "Lung findings on high resolution CT in early ankylosing spondylitis," European Journal of Radiology, vol. 47, no. 1, pp. 71-76, 2003.

[20] A. El Maghraoui, S. Chaouir, A. Abid et al., "Lung findings on thoracic high-resolution computed tomography in patients with ankylosing spondylitis. Correlations with disease duration, clinical findings and pulmonary function testing," Clinical Rheumatology, vol. 23, no. 2, pp. 123-128, 2004.

[21] A. S. Souza Jr., N. L. Müller, E. Marchiori, L. V. SoaresSouza, and M. de Souza Rocha, "Pulmonary abnormalities in ankylosing spondilitis: inspiratory and expiratory highresolution CT findings in 17 patients," Journal of Thoracic Imaging, vol. 19, no. 4, pp. 259-263, 2004.

[22] R. Altin, S. Özdolap, A. Savranlar et al., "Comparison of early and late pleuropulmonary findings of ankylosing spondylitis by high-resolution computed tomography and effects on patients' daily life," Clinical Rheumatology, vol. 24, no. 1, pp. 22-28, 2005.

[23] F. F. Ayhan-Ardic, O. Oken, Z. R. Yorgancioglu, N. Ustun, and F. D. Gokharman, "Pulmonary involvement in lifelong nonsmoking patients with rheumatoid arthritis and ankylosing spondylitis without respiratory symptoms," Clinical Rheumatology, vol. 25, no. 2, pp. 213-218, 2006.

[24] P. D. Sampaio-Barros, E. M. Cerqueira, S. M. Rezende et al., "Pulmonary involvement in ankylosing spondylitis," Clinical Rheumatology, vol. 26, no. 2, pp. 225-230, 2007.

[25] S. Baser, S. Cubukcu, S. Ozkurt, N. Sabir, B. Akdag, and E. Diri, "Pulmonary involvement starts in early stage ankylosing spondylitis," Scandinavian Journal of Rheumatology, vol. 35, no. 4, pp. 325-327, 2006.

[26] A. El-Maghraoui, S. Chaouir, A. Bezza et al., "Thoracic high resolution computed tomography in patients with ankylosing spondylitis and without respiratory symptoms," Annals of the Rheumatic Diseases, vol. 62, no. 2, pp. 185-186, 2003.

[27] M. Remy-Jardin, J. L. Edme, C. Boulenguez, J. Remy, I. Mastora, and A. Sobaszek, "Longitudinal follow-up study of smoker's lung with thin-section CT in correlation with pulmonary function tests," Radiology, vol. 222, no. 1, pp. 261270, 2002.

[28] J. Braun, X. Baraliakos, J. Listing et al., "Persistent clinical efficacy and safety of anti-tumour necrosis factor $\alpha$ therapy with infliximab in patients with ankylosing spondylitis over 5 years: evidence for different types of response," Annals of the Rheumatic Diseases, vol. 67, no. 3, pp. 340-345, 2008.

[29] J. Braun, J. Davis, M. Dougados, J. Sieper, S. van der Linden, and D. van der Heijde, "First update of the international ASAS consensus statement for the use of anti-TNF agents in patients with ankylosing spondylitis," Annals of the Rheumatic Diseases, vol. 65, no. 3, pp. 316-320, 2006.

[30] A. J. Ostor, A. J. Crisp, M. F. Somerville, and D. G. Scott, "Fatal exacerbation of rheumatoid arthritis associated fibrosing alveolitis in patients given infliximab," British Medical Journal, vol. 329, no. 7477, p. 1266, 2004.

[31] E. Bargagli, M. Galeazzi, and P. Rottoli, "Infliximab treatment in a patient with rheumatoid arthritis and pulmonary fibrosis," European Respiratory Journal, vol. 24, no. 4, p. 708, 2004.

[32] J. Ledingham, C. Wilkinson, and C. Deighton, "British Thoracic Society (BTS) recommendations for assessing risk and managing tuberculosis in patients due to start anti-TNF$\alpha$ treatments," Rheumatology, vol. 44, no. 10, pp. 1205-1206, 2005. 


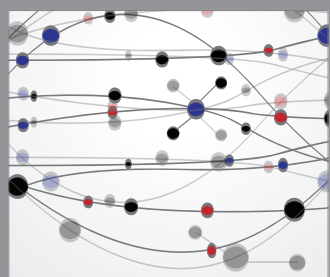

The Scientific World Journal
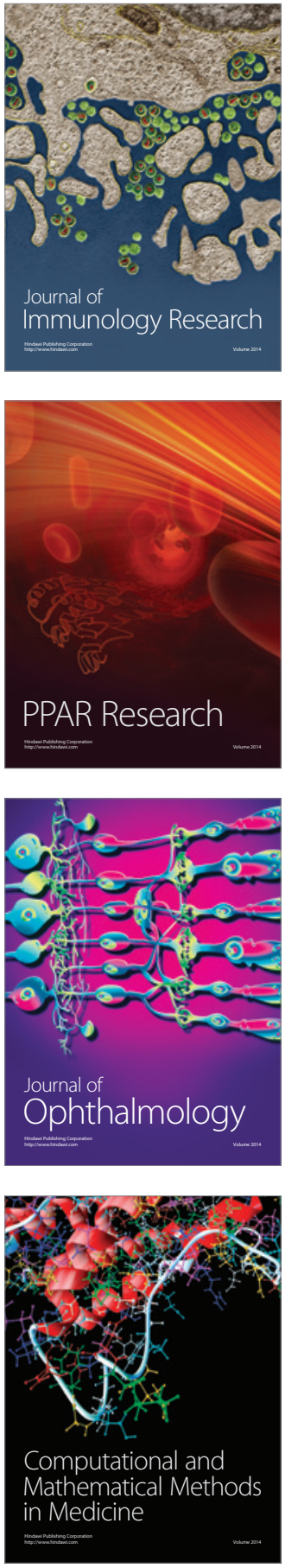

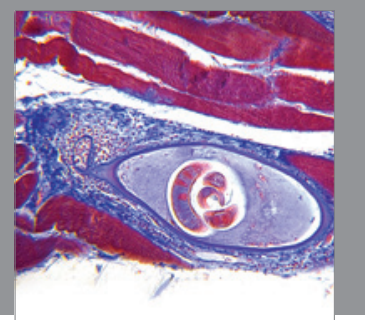

Gastroenterology

Research and Practice
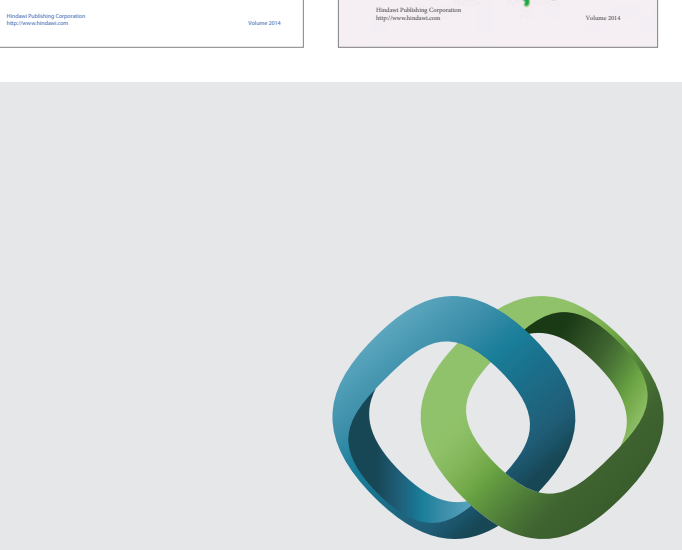

\section{Hindawi}

Submit your manuscripts at

http://www.hindawi.com
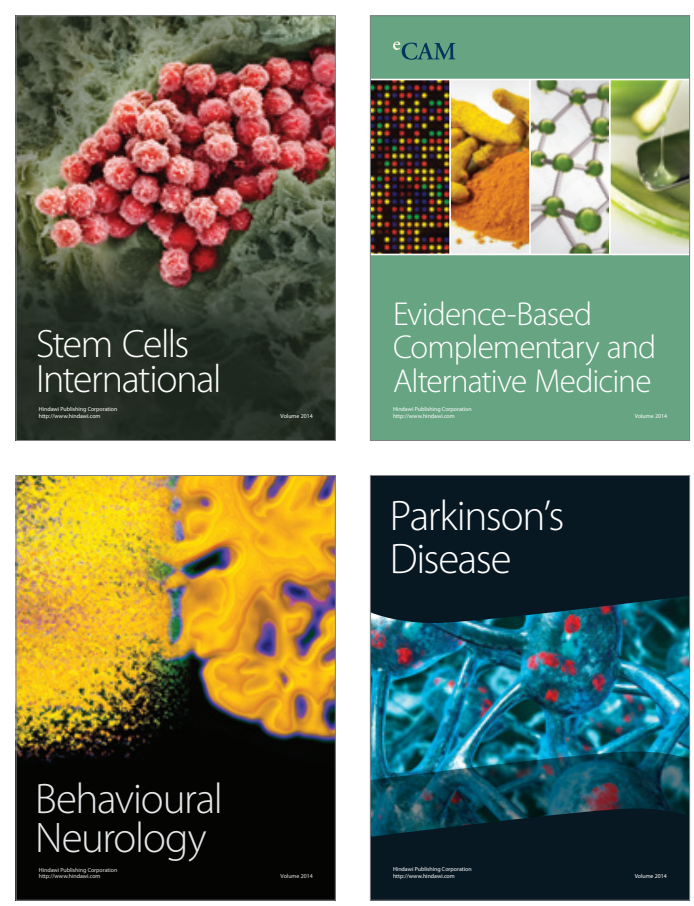

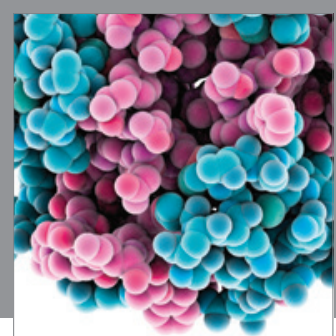

Journal of
Diabetes Research

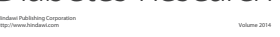

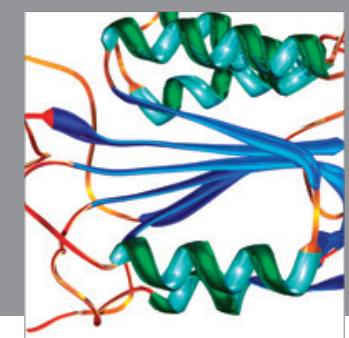

Disease Markers
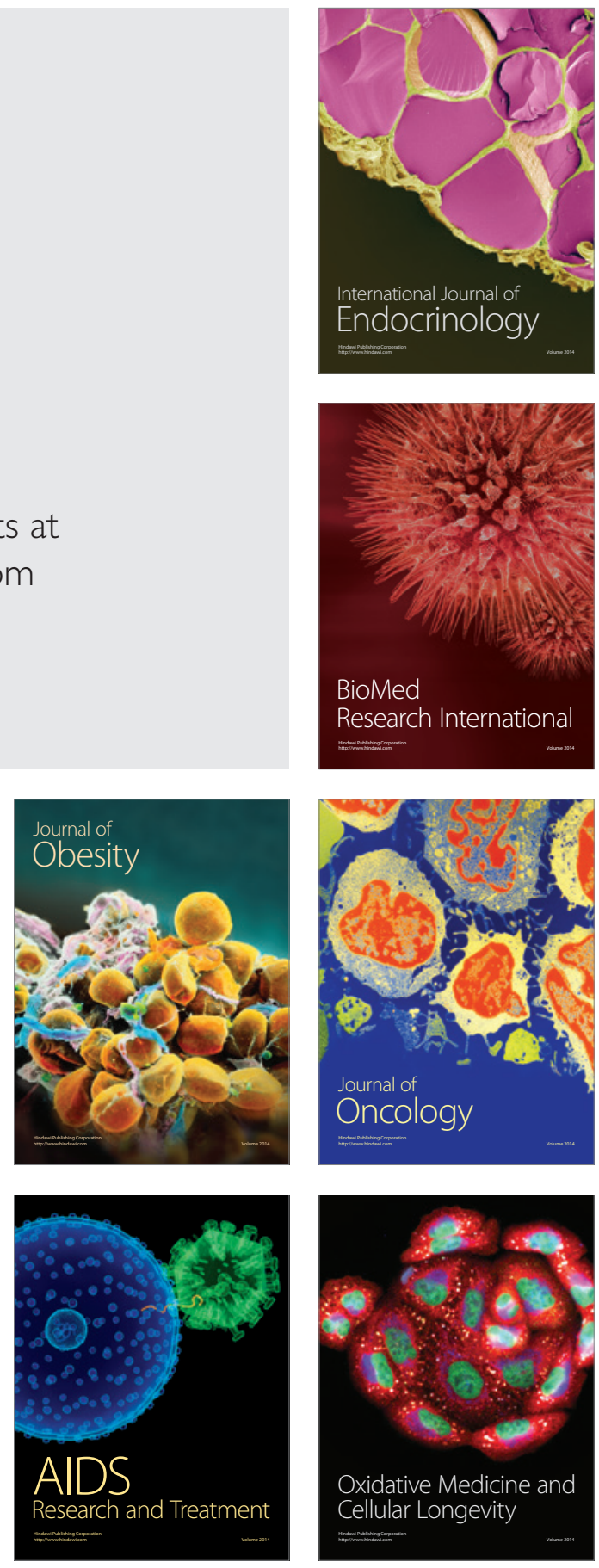